\title{
Antiglycative and carbonyl trapping properties of the water soluble fraction of coffee silverskin
}

\author{
M. Mesías a, M. Navarro a, N. Martínez-Saez b, M. Ullate b, M.D. del Castillo b, F.J. Morales a \\ a Institute of Food Science, Technology and Nutrition, ICTAN-CSIC, 28040Madrid, Spain \\ ${ }^{b}$ Institute of Food Science Research (CIAL-CSIC-UAM), 28049 Madrid, Spain
}

\begin{abstract}
Carbonyl stress and accumulation of advanced glycation end-products (AGEs) in human tissues are involved in diabetic complications, atherosclerosis, Alzheimer's disease and aging. The objective of this study was to evaluate the in vitro protective effect of aqueous extracts of coffee silverskin (CS) in the formation of AGEs and trapping of carbonyl reactive species such as methylglyoxal (MGO). Aqueous extracts of CS from Arabica and Robusta coffee varieties were obtained under environment friendly extraction conditions. CS extracts were characterized by the analysis of dietary fiber, caffeine, chlorogenic acids (CGAs), total phenolic compounds, browning, melanoidins, and antioxidant capacity. CS extracts and CGA exhibited a dose-dependent anti-AGE capacity in the protein-glucose model system $\left(37^{\circ} \mathrm{C} / 2 \mathrm{I}\right.$ days $)$ with an IC50 of 0.6 $\mathrm{mg} / \mathrm{mL}$ and $0.4 \mathrm{mg} / \mathrm{mL}$, respectively. Caffeine did not prevent AGE formation under the studied conditions. Regardless to protein-MGO assay $\left(37^{\circ} \mathrm{C} / 14\right.$ days), the anti-AGE capacity of CS extracts and CGA was also dose-dependent with an IC50 of $1.3 \mathrm{mg} / \mathrm{mL}$ and $0.1 \mathrm{mg} / \mathrm{mL}$, respectively. Caffeine weakly inhibited the reaction of protein and MGO. The MGO trapping capacity was established as a model for protection against carbonyl stress. Robusta CS was very effective for the direct trapping of MGO with an IC50 of $0.055 \mathrm{mg} / \mathrm{mL}$ as compared with Arabica CS (IC50 of $0.6 \mathrm{mg} / \mathrm{mL}$ ). CGA and caffeine showed an IC50 for MGO trapping capacity of $0.14 \mathrm{mg} / \mathrm{mL}$ and N10 mg/mL, respectively. The highest CGA content in the Robusta CS extract could explain its higher MGO trapping activity as compared with the Arabica CS extract. The anti-AGE and MGO trapping capacities of CS may be associated to other chemical components besides CGA. In conclusion, aqueous CS extract may be considered as a natural source of inhibitors of in vitro formation of AGEs and carbonyl stress. The inhibitory effect of the coffee extracts may be associated to their carbonyl trapping capacity.
\end{abstract}

\section{INTRODUCTION}

AGEs (advanced glycation end-products) are the final products derived from the Maillard reaction or nonenzymatic glycation process produced in the human body. It is known that AGEs are involved in the development of several health disorders such as diabetes and its complications (Vlassara \& Palace, 2002), atherosclerosis (Vlassara, 1996), Alzheimer's disease and normal aging (Münch, Thome, Foley, Schinzel, \& Riederer, 1997). In addition, the increase in reactive carbonyls in tissues is known as carbonyl stress which leads to directly increase chemical modification of proteins (glycation) and lipids (lipoxidation) in diabetes. Reactive carbonyl species generated from carbohydrate, lipid and amino acid metabolism such as methylglyoxal (MGO), glyoxal, glyoxalaldehyde, dehydroascorbate, 3-deoxyglucosone and malondialdehyde, are potent precursors of AGE formation and protein cross-linking (Thornalley, Langborg, \& Minhas, 1999). MGO derived AGE structures, including CEL ( $\mathrm{N}$-epsilon-(carboxyethyl)-lysine) and MOLD (methylglyoxallysine dimer), are increased in diabetes (Baynes \& Thorpe, 1999). Thus, preventing AGE formation/accumulation may control significantly the pathogenesis of diabetes complications.

The inhibition of AGE formation might follow several mechanisms involving, e.g., aldose reductase, antioxidant activity, reactive dicarbonyl trapping, sugar autoxidation inhibition and amino group binding, where the antiglycative activity of phytochemicals has been usually linked to oxidative reactions (Bousová et al., 2005). The inhibition of AGE formation by some synthetic compounds such as aminoguanidine (AG) has been well documented. However, this compound has been associated with several adverse effects in in vivo studies (Thornalley, 2003; Williams, 2004) since it is a highly reactive nucleophilic reagent that reacts with many biological molecules (pyridoxal phosphate, pyruvate, glucose, malondialdehyde, and others). Hence, the search for natural products which can inhibit AGE formation has recently been an objective of worldwide research (Peng, Cheng, et al., 2008; Povichit, Phrutivorapongkul, Suttajit, Chaiyasut, \& Leelapornpisid, 2010; Wang, Sun, Cao, \& Tian, 2009). 
Coffee consumption has been associated with reduction in chronic disease risk such as type 2 diabetes (Van Dam \& Hu, 2005). Coffee has been suggested as a potential natural source of inhibitors of AGEs. Verzelloni, Tagliazucchi, Rio, Calani, and Conte (20II) stated that coffee melanoidins inhibit the formation of AGEs by (i) acting as a radical scavenger and an Fe-chelator in the post-Amadori phase of the glycation reaction and (ii) inhibiting dicarbonyl reactive compound formation during glucose autoxidation. However, only chlorogenic acid (CGA) effectively inhibits protein glycation and dicarbonyl compound formation.

CS is the tegument of green coffee beans (outer layer) and is the major by-product of the roasting procedure (Napolitano, Fogliano, Tafuri, \& Ritieni, 2007). CS is characterized by the presence of high amounts of dietary fiber and antioxidant activity (Borrelli, Esposito, Napolitano, Ritieni, \& Fogliano, 2004; Napolitano et al., 2007), and contains several bioactive compounds with potential application in food and health (Pourfarzad, Mahdavian-Mehr, \& Sedaghat, 20I3). Indeed, CS has been proposed as a functional ingredient due to its health promoting properties (Esquivel \& Jiménez, 20I2). The use of aqueous extracts of coffee silverskin (CS) as health promoter has been recently proposed (del Castillo et al., 2013; MartinezSaez et al., 2014). Among other bioactive compounds, the extract containsCGA and its health benefits have been in part associated to the presence of this bioactive phytochemical. No studies on the effect of the aqueous CS extract as a natural source of scavengers of dicarbonyls and its anti-AGE properties have been reported which are of great interest and it is the goal of the present investigation.

\section{MATERIALS AND METHODS}

\section{Materials and reagents}

Coffee silverskin from Arabica (Coffea arabica) and Robusta (Coffea canephora) varieties were provided by Fortaleza S.A. (Spain). According to the manufacturer the weight portion of the coffee silverskin represents $0.5 \%$ of the green beans and $0.6 \%$ of the roasted beans.

Bovine serum albumin (BSA), 40\% methylglyoxal solution (MGO), sodium azide, aminoguanidine (AG), 5methylquinoxaline (5-MQ), ophenyldiamine (OPD), 2,2-diphenyl-I-picrylhydrazyl (DPPH), fluorescein disodium, 2,2'-azobis(2-amidinopropane) dihydrochloride (AAPH), trolox (6-hydroxy-2,5,7,8tetramethylchroman-2-carboxylic acid), potassium persulfate, ammonium bicarbonate, caffeine (CFF) and chlorogenic acid (CGA) standards were purchased from Sigma (St. Louis, MO, USA). Folin-Ciocalteu reagent, iron(III) chloride, sodium phosphate monobasic, sodium bicarbonate, hydrogen peroxide, sodium chloride, chloroform, and hydrochloric acid were obtained from Panreac (Madrid, Spain). 2,2'-Azobis-(3ethylbenzothiazoline-6-sulfonic acid) (ABTS), 2,4,6-tri(2-pyridyl)-striazine (TPTZ), 2,2-azobis (methylpropionamidine) dihidro (AAPH) and piridoxamine were purchased from Fluka Chemical (Madrid, Spain). Fiber kit was from Megazyme International Ireland Ltd. Methanol, acetonitrile, glacial acetic acid, potassium hexacyanoferrate and zinc sulfate were purchased from Merck (Darmstadt, Germany). Milli-Q water used was produced using an Elix3 Millipore water purification system coupled to a Milli-Q module (model Advantage 10) (Millipore, Molsheim, France). All other chemicals and reagents were of analytical grade.

\section{Equipments}

Synergy ${ }^{\mathrm{TM}} \mathrm{HT}$-multimode microplate reader with an automatic reagent dispense and temperature control from Biotek Instruments (VT, USA), capillary electrophoresis apparatus Agilent GI6000A (Agilent, Madrid, Spain) and HPLC Shimadzu (Kyoto, Japan) equipped with a LC-20AD pump, a SIL-IOADvp autosampler, a CTO-IOASVP oven, and a DAD (SPD-M20A).

\section{Preparation of soluble extracts from coffee silverskin}

Arabica and Robusta CS extracts were prepared by aqueous extraction according to the procedure patented by del Castillo et al. (20l3b). Briefly, $50 \mathrm{~mL}$ of boiling water was added to $2.5 \mathrm{~g}$ of coffee silverskin. The mixture was stirred at $250 \mathrm{rpm}$ for $10 \mathrm{~min}$, filtered by Whatman paper no. 4 and the filtrate was freeze dried. The powdered extracts were stored in dark and dry place until analysis.

\section{Determination of total, soluble and insoluble fiber}

Total, soluble and insoluble dietary fibers of CS extracts were determined by an enzymatic-gravimetric method based on the AOAC methods 991.43 and 985.29 (Lee, Prosky, \& De Vries, 1992; Prosky, Asp, 
Schweizer, Devries, \& Furda, 1988, 1992) and employing a commercial kit. All measurements were performed in triplicate. Results were expressed as $\mathrm{mg}$ fiber/g CS extracts.

\section{Determination of melanoidins}

Melanoidin content of CS extracts $(\mathrm{I} \mathrm{mg} / \mathrm{mL})$ was determined according to Silván, Morales, and SauraCalixto (2010). Extracts were then subjected to ultrafiltration using a Microcon YM- I0 regenerated cellulose $10 \mathrm{kDa}$ (Millipore, Bedford, MA) at $12000 \mathrm{~g}$ for $10 \mathrm{~min}$. Melanoidin content was measured spectrophotometrically at $405 \mathrm{~nm}$. Results were expressed as $\mathrm{mg} / \mathrm{g}$ CS extracts.

\section{Determination of CGA and caffeine}

The procedure for the determination of CGA and caffeine was performed according to del Castillo, Ames, and Gordon (2002). The separation was carried out in a capillary electrophoresis system provided with an ultraviolet visible detection system. Calibration curves of caffeine and CGA were constructed. The analyses were performed in triplicate. Results were expressed as $\mathrm{mg} / \mathrm{g}$ CS extracts.

\section{Browning determination}

Browning was measured at $405 \mathrm{~nm}$ using a microplate reader. CS extracts were dissolved in water at 10 $\mathrm{mg} / \mathrm{mL}$ in order to obtain an absorbance reading less than 1.5 arbitrary units. All the measurements were made in triplicate. Results were expressed as absorbance units/g CS extracts.

\section{Determination of total phenolic content}

Total phenolic content (TPC)was determined by the Folin-Ciocalteu method as described by Contini, Baccelloni, Massantini, and Anelli (2008). CGA calibration curve was used for quantification. All measurements were performed in triplicate. Results were expressed as mg CGA equivalent/g CS extract.

\section{ABTS+. assay}

ABTS+. assay estimated in terms of radical scavenging activity was employed for determining the antioxidant capacity of the extracts as described by Mesías, Navarro, Gökmen, and Morales (2013). Absorbance reading was taken using a microplate reader. Aqueous solutions of Trolox at various concentrationswere used for calibration. All measurements were performed in triplicate. Results were expressed as $\mu$ mol Trolox equivalent antioxidant capacity (TEAC)/g CS extract.

\section{ORAC assay}

ROO- scavenging activity was measured by monitoring the fluorescence decay as result of ROO-induced oxidation of fluorescein, known as the oxygen radical absorbance capacity (ORAC) assay as described by Dávalos, Gómez-Cordovés, and Bartolomé (2004). ORAC values were expressed as Trolox equivalents by using the standard curve calculated for each assay and the final results were expressed in $\mu$ mol equivalents of Trolox/g CS extract. All measurements were performed in triplicate.

\section{FRAP assay}

Ferric reducing antioxidant power (FRAP) was determined as described by Morales, Martin, Açar, ArribasLorenzo, and Gökmen (2009). Aqueous solutions of Trolox at various concentrations were used for calibration. All measurements were performed in triplicate. Results were expressed as $\mu \mathrm{mol} \mathrm{TEAC/g} C S$ extract.

\section{DPPH assay}

DPPH radical-scavenging activity was determined as described by Morales et al. (2009). Aqueous solutions of Trolox at various concentrations were used for calibration. All measurements were performed in triplicate. Results were expressed as $\mu \mathrm{mol} \mathrm{TEAC} / \mathrm{g}$ CS extract.

\section{In vitro glycation assay with BSA-glucose}

BSA-glucose (BSA-Glc) assay was based on Peng, Cheng, et al. (2008). Briefly, BSA (35 mg/mL) and glucose $(175 \mathrm{mg} / \mathrm{mL})$ were dissolved in phosphate buffer $(0.1 \mathrm{M}, \mathrm{pH} 7.4)$. BSA solution also contained $0.1 \mathrm{~g} / \mathrm{mL}$ sodium azide. BSA solution $(200 \mu \mathrm{L})$ was incubated with glucose solution $(400 \mu \mathrm{L})$ at $37^{\circ} \mathrm{C}$ for $2 \mathrm{I}$ days in the absence or the presence $(100 \mu \mathrm{L})$ of soluble CS extracts, caffeine, or CGA (concentration of the stock 
solutions at I, 5 , and $10 \mathrm{mg} / \mathrm{mL}$ ). In parallel, CS extracts and standards were incubated at $37^{\circ} \mathrm{C}$ for $2 \mathrm{I}$ days in order to measure their intrinsic fluorescence. The final concentration of each reactant in the reaction medium was: $10 \mathrm{mg} / \mathrm{mL}$ for BSA, $100 \mathrm{mg} / \mathrm{mL}$ for glucose, $0.6 \mathrm{mg} / \mathrm{mL}$ for $A G$, and $0.14,0.71$ or $1.42 \mathrm{mg} / \mathrm{mL}$ for the different solutions of caffeine, CGA, and CS extracts. The IC50 values (concentration in $\mathrm{mg} / \mathrm{mL}$ required to inhibit glycation by $50 \%$ ) were calculated from the dose-response curves using Microsoft-Excel computer software.

\section{In vitro glycation assay with BSA-MGO}

BSA-MGO assay was performed according to Lunceford and Gugliucci (2005) with minor modifications. Briefly, BSA $(35 \mathrm{mg} / \mathrm{mL})$ and MGO $(0.4 \mathrm{mg} / \mathrm{mL})$ solutions were prepared in phosphate buffer $(0.1 \mathrm{M}, \mathrm{pH} 7.4)$. Two hundred microliters of BSA solution, containing $0.1 \mathrm{~g} / \mathrm{mL}$ sodium azide, was incubated with $400 \mu \mathrm{L}$ of MGO solution. The incubation was carried out at $37^{\circ} \mathrm{C}$ for 14 days in the absence or the presence $(100 \mu \mathrm{L})$ of soluble CS extracts, caffeine, or CGA (concentration of the stock solutions at I, 5 , and $10 \mathrm{mg} / \mathrm{mL}$ ). In parallel, CS extracts and standards were incubated at $37^{\circ} \mathrm{C}$ for 14 days in order to measure their intrinsic fluorescence. The final concentration of each reactant in the reaction medium was $10 \mathrm{mg} / \mathrm{mL}$ for BSA, 0.23 $\mathrm{mg} / \mathrm{mL}$ for MGO, $0.6 \mathrm{mg} / \mathrm{mL}$ for $A G$ and $0.14,0.7 \mathrm{I}$ and $1.42 \mathrm{mg} / \mathrm{mL}$ for the different solutions caffeine, CGA and CS extracts. The IC50 values were calculated from the dose-response curves using Microsoft-Excel computer software.

\section{AGE fluorescence measurement}

The measurement of fluorescent intensity of total AGEs and the intrinsic fluorescence of the CS extracts and standards after incubation were performed using a microplate spectrophotometer. The presence of total AGEs was characterized by a typical fluorescence with excitation and emission maxima at 360 and 420 $\mathrm{nm}$, for BSA-Glc assay and 340 and $420 \mathrm{~nm}$, for BSA-MGO assay. Percentage inhibition of AGE formation by each sample was calculated using the following equation; \% inhibition = [I - ((fluorescence of the solution with inhibitors -intrinsic fluorescence of the samples) / fluorescence of the solution without inhibitors)] $\times$ $100 \%$.

\section{Evaluation of direct MGO trapping capacity}

Direct MGO trapping capacity was as described by Peng, Zheng, et al. (2008) with some modifications (Mesías et al., 2013). Pyridoxamine (PM) was used as the positive control. The final concentration of each reactant in the reaction medium was $0.04 \mathrm{mg} / \mathrm{mL}$ for $\mathrm{MGO}, 0.1 \mathrm{mg} / \mathrm{mL}$ for $\mathrm{PM}$ and a range of $0.00 \mathrm{I}-0.5$ $\mathrm{mg} / \mathrm{mL}$ for soluble CS extracts, caffeine and CGA. Sampleswere incubated at $37^{\circ} \mathrm{C}$ for $168 \mathrm{~h}$, after that 200 $\mu \mathrm{L}$ of OPD was added. The unreacted MGO was quantified by HPLC (Shimadzu, Kyoto, JP) on the basis of the amount of the derivatized product, 2-methylquinoxaline (2-MQ). The chromatographic separation was carried out on a Mediterranean-Sea-ODS2 column (I50 × $3 \mathrm{~mm}, 5 \mu \mathrm{m}$, Tecknokroma, Barcelona, Spain). The amounts of unreacted MGO in the samples could be determined on the basis of the ratios of peak area of 2-MQ and 5-MQ. Percentage decrease in MGO was calculated using the following equation: MGO decrease \% $=[$ (amounts of MGO in control - amounts of MGO in sample or PM solution) / amounts of MGO in control] $\times 100 \%$. The IC50 values of samples were calculated from the dose-response curves using Microsoft- Excel computer software.

\section{Statistical analysis}

Statistical analyses were performed using the Statgraphics Centurion XV statistical program (Herndon, VA). Data were expressed as the mean value \pm SD. Analysis of variance (ANOVA) and the Duncan test were applied to determine differences between means. Differences were considered to be significant at $\mathrm{p} \mathrm{b} 0.05$.

\section{RESULTS AND DISCUSSION}

Table I summarizes the content in dietary fiber (total, soluble and insoluble), melanoidins, chlorogenic acids, caffeine, total phenolic, antioxidant and browning of water soluble CS extracts. TPC was of 31.0 and $35.4 \mathrm{mg}$ equivalents CGA/g for Arabica and Robusta CS extracts, respectively. CS has previously been considered a good source of phenolic compounds (Bresciani, Calani, Bruni, Brighenti, \& Del Rio, in press). CGA content was significantly higher in Robusta CS extract $(68.52 \mathrm{mg} / \mathrm{g})$ than in Arabica CS extract (II.18 mg/g). Results of CGA are in line with those reported by Narita and Inouye (20I2) and del Castillo et al. (20I3). In a similar way, caffeine content was also higher in Robusta CS extract $(33.98 \mathrm{mg} / \mathrm{g})$ in comparison with Arabica 
CS extracts $(30.26 \mathrm{mg} / \mathrm{g})$. For browning determination and melanoidin content, moreover, these differences were significant. These results agree with those from Martinez-Saez et al. (2014) who described that levels of CGA, caffeine concentration, melanoidins and browning, expressed as color, were significantly greater ( $P$ b 0.05) in beverages made with Robusta coffee silverskin extract than Arabica.

The antioxidant capacity (radical scavenging, and hydrogen and electron donating capacities) of the CS extracts was assessed by ABTS, ORAC, DPPH and FRAP assays, showing results of 85.20, 1194, 829.8 and $219.9 \mu \mathrm{mol}$ TEAC/g sample in the case of Arabica CS extract and 225.8, 15I3, 640.1 and $231.3 \mu \mathrm{mol}$ TEAC/g sample for Robusta CS extract. Arabica CS extract showed higher reducing power than Robusta CS extract. In contrast, Robusta CS extract showed significantly higher scavenging properties against the ABTS radical than Arabica CS extract. The results agree with those described by Napolitano et al. (2007), del Castillo et al. (20/3) and Martinez-Saez et al. (20/4), who found, a higher proportion of extractable antioxidants in aqueous solution for the samples of Robusta silverskin, in comparison with Arabica. The differences found in the total antioxidant capacity values in ACS and RCS extracts may be related to those detected by analyzing their components, melanoidins and CGA since, as it has been suggested, these compounds contribute to the antioxidant properties of coffee silverskin.

Fig. I shows the effect of CS extracts, caffeine, and chlorogenic acid on the formation of fluorescent AGEs in glycation model systems composed by BSA and glucose treated at $37^{\circ} \mathrm{C}$ for 21 days. Caffeine did not affect the formation of AGEs under our particular conditions. CGA showed antiglycative capacity being its IC50 value of $0.4 \mathrm{mg} / \mathrm{mL}$. Kim et al. (20I I) already described the antiglycative capacity of CGA in the formation of fluorescent AGEs and crosslinking of collagen. Arabica and Robusta CS extracts showed similar and dosedependent rates of AGE inhibition with an IC50 of $0.6 \mathrm{mg} / \mathrm{mL}$ for both extracts. The only significant differences ( $p \quad b \quad 0.05$ ) were found at the concentration of $0.71 \mathrm{mg} / \mathrm{mL}$ where ACS showed a significantly higher antiglycative activity than RCS.

Fig. 2 represents the antiglycative capacity of the Arabica and Robusta CS extracts, caffeine, and chlorogenic acid in glycoxidation model systems (BSA-MGO) at $37{ }^{\circ} \mathrm{C}$ for 14 days. MGO was reported as a potent agent for AGE generation and modified proteins irreversibly by targeting the side chains of arginine at a much faster rate than reducing sugars (Oya et al., 1999). Caffeine $(1.4 \mathrm{mg} / \mathrm{mL}$ ) exerted a weak antiglycative capacity corresponding to $10 \%$ of the inhibition of the formation of fluorescent AGEs. The antiglycative capacity of CGA was notably higher in the BSA-MGO assay (IC50 of $0.1 \mathrm{mg} / \mathrm{mL}$ ) as compared with the BSA-glucose assay. However, the antiglycative capacity of Arabica and Robusta CS extracts was lower (IC50 of $1.3 \mathrm{mg} / \mathrm{mL}$ ) as compared with the BSA-glucose assay. Again, significant differences between both CS extracts were not observed, and they behaved in a dose-dependent manner.

AGE formation can be suppressed by inhibitors at the post-Amadori stage which can scavenge carbonyl precursors. As a consequence, the direct MGO-trapping capacity of Arabica and Robusta CS extracts was determined. Fig. 3 shows the MGO trapping ability of the CS extracts at $168 \mathrm{~h}$ in a range of concentrations from 0.001 to $0.5 \mathrm{mg} / \mathrm{mL}$. Pyridoxamine $(0.1 \mathrm{mg} / \mathrm{mL})$ was used as control since it reacts with methylglyoxal to form stable adducts (Nagaraj et al., 2002). IC50 value for PM was $0.006 \mathrm{mg} / \mathrm{mL}$. Caffeine, chlorogenic acid, and the Arabica and Robusta CS extracts trapped MGO in a dose-dependent manner. The lowest effectiveness was shown by the caffeine whereas only $20 \%$ of the initial MGO was decreased in the presence of $0.5 \mathrm{mg} / \mathrm{mL}$ caffeine. MGO was effectively quenched by CGA with an IC50 of $0.14 \mathrm{mg} / \mathrm{mL}$. Arabica and Robusta CS extracts showed significant differences in their ability to trap MGO with an IC50 of 0.055 and $0.65 \mathrm{mg} / \mathrm{mL}$ for Robusta and Arabica CS extracts, respectively. Robusta CS extract was nearly 10 -fold more active against MGO than Arabica CS extract.

To get more insight into the MGO trapping capacity of the extracts, kinetic evaluation for MGO-trapping capacity for $168 \mathrm{~h}$ at a concentration of $0.1 \mathrm{mg} / \mathrm{mL}$ was performed and compared with that of the PM (Fig. 4). PM and Robusta CS extract already trapped 50\% of the initial MGO in the systemat 27 and $66 \mathrm{~h}$, respectively. In contrast, the Arabica CS extract only reached to trap around I4\% of the MGO at $168 \mathrm{~h}$, which showed a significant lower MGO-trapping capacity of this extract. The MGO-trapping capacity of the Arabica and Robusta CS extracts increased continuously during the time of incubation at $37^{\circ} \mathrm{C}$, following the same trend as to that of PM. 
In the present study the antiglycative capacity measured as the inhibition of the formation of fluorescent AGEs, and mitigation of carbonyl radical stress (in terms of MGO-trapping capacity) of Arabica and Robusta CS aqueous extracts have been demonstrated. These results are in agreement with Verzelloni, Pellacani, et al. (20II) and Verzelloni, Tagliazucchi, et al. (20II) who reported that coffee contains molecules with in vitro antiglycative capacity. Our investigation demonstrates that antiglycative properties are also maintained in coffee by-products which may be related to phenolic compounds naturally present in coffee beans (Napolitano et al., 2007) and melanoidins formed through Maillard reaction during roasting (DelgadoAndrade \& Morales, 2005). According to Borrelli et al. (2004) antioxidant compounds present in coffee can form covalent links with carbohydrates resulting in a fiber-antioxidant complex. Specifically the phenolic compounds from CS, mainly chlorogenic acid, may react with polysaccharide components forming melanoidins, which exerts the antioxidant activity (Borrelli, Visconti, Mennella, Anese, \& Fogliano, 2002). According to Verzelloni, Pellacani, et al. (20II) and Verzelloni, Tagliazucchi, et al. (20II) the high molecular weight compound fraction of coffee has high antioxidant, chelating and antiglycative activities. Chlorogenic acid and fiber contents were significantly higher in Robusta CS extract as compared with Arabica CS extract.

Antiglycative effects of phenolic compounds have been previously reported. These compounds can exert their inhibition through their antioxidant properties, scavenging of free radicals, and quenching of carbonyl radical species (Delgado-Andrade \& Morales, 2005; Kim \& Kim, 2003; Sang et al., 2007; Wu \& Yen, 2005). Wu, Hsieh, Wang, and Chen (2009) evaluated the ability of phenolic acids to inhibit glycation, concluding that these compounds were effective in the prevention of glucose-mediated protein modification, which are considered potent inhibitors of both AGE formation and the subsequent crosslinking of proteins. Among the phenolic acids studied by these authors, chlorogenic acid was considered to be one of the major antiglycative compounds, being in line with our results. In a similar way, Gugliucci, Bastos, Schulze, and Souza (2009) reported for yerba mate water extract containing chlorogenic acid and caffeic acid a high percentage of AGE fluorescence inhibition.

As mentioned above, the present investigation was carried out using aqueous extracts in order to perform a cost-effective and environmentally friendly procedure, as well as being more interesting from safety and toxicological points of view for their industrial application. Several authors have evaluated the influence of the extraction process on the antioxidant capacity, concluding that water is highly efficient at extracting antioxidants. In this sense, Budryn et al. (2009) reported that both chlorogenic acids and melanoidins were found in higher amounts in aqueous extracts than in ethanolic extracts from green and roasted coffee, showing that these antioxidants were more soluble in water. In a similar way, Yen,Wang, Chang, and Duh (2005) indicated that the highest antioxidant yields in extracts were obtained with water from roasted coffee residues. Furthermore, Bravo, Monente, Juániz, De Peña, and Cid (2013) stated that water is necessary to extract more phenolic and nonphenolic antioxidants from spent coffee. Consequently, it can be supposed that the aqueous CS extracts contain the majority of the antioxidant compounds present in the CS including chlorogenic acid and, hence, it might justify the high antiglycative activity of the extracts.

Regarding caffeine, it has been shown that this compound has a low in vitro antioxidant activity (Somoza et al., 2003; Yen et al., 2005). In addition, caffeine has displayed a low inhibitory effect on AGE formation in in vitro assay systems (Nakagawa, Yokozawa, Tarasawa, Shu, \& Juneja, 2002). These findings are in accordance with those found in the present study, since caffeine practically did not exhibit any antiglycative effect in the assays of BSA-glucose and BSA-MGO and a low MGO trapping capacity in comparison with that found for CS extracts. However, reactive oxygen species scavenging has been recently proposed for caffeine (LeonCarmona \& Golano, 20I I).

Concerning the MGO-trapping capacity, Robusta CS extract trapped MGO more rapidly and efficiently as compared with Arabica CS extract. It might be indicated that the different compositions of the extracts influenced their MGO-trapping ability but not significantly the antiglycative capacity in the protein assays. Although FRAP and DPPH assays did not show large differences among Arabica CS and Robusta CS extracts, ABTS and ORAC exhibited a higher antioxidant capacity in the Robusta variety. In addition, despite no differences were observed in total phenolic content of the two studied samples, CGA content and specifically 3-CGA, 4-CGA and 5-CGA contents were also higher in the Robusta specie (8.2, 9.I and 26.3 
$\mathrm{mg} / \mathrm{g}$ versus 1.5 , 1.8 and $6.4 \mathrm{mg} / \mathrm{g}$ in Arabica CS), which could explain the major antiglycative capacity of this extract. On the other hand, it should be taken into account that the presence of several AGE inhibitors in an extract may have synergistic effects (Chompoo, Upadhyay, Kishimoto, Makise, \& Tawata, 20I I). During coffee roasting, a part of CGA is incorporated into the melanoidins (Moreira, Nunes, Domingues, \& Coimbra, 2012) and the new structures may contribute to the overall antiglycative capacity of the CS extracts. Specifically, according to Rice-Evans, Miller, and Paganga (1996), phenolic compounds may have synergistic or antagonistic effects among them or with other constituents of an extract. Therefore, it can be supposed that chlorogenic acid together with other phenolic compounds, and CGA-melanoidins rich might contribute overall to the antiglycative activity of the extracts.

In spite of the antiglycative properties of the aqueous extract of coffee silverskin demonstrated in the in vitro assays in the present study, it cannot be assured that this effect also occur in in vivo experiments. According to Verzelloni, Pellacani, et al. (20II) and Verzelloni, Tagliazucchi, et al. (20II), after ingestion by humans polyphenolic compounds can be metabolized generating different metabolites in the colon, which can or not exert inhibitory activity against AGE formation. These observations may be taken into account for future research.

\section{CONCLUSIONS}

The antiglycative capacity of coffee silverskin (CS) extracts, obtained from Arabica and Robusta varieties, was evaluated using different in vitro models. Both Arabica and Robusta CS extracts exhibited an anti-AGE capacity in BSA-glucose and BSA-MGO assays at concentrations ranging from 0.1 to $1.5 \mathrm{mg} / \mathrm{mL}$. No significant differences among the Arabica and Robusta CS extracts were observed. On the other hand, the direct MGO-trapping assay showed that the CS extracts trapped MGO in a dose-dependent manner, but the Robusta CS extract showed a higher trapping capacity $(\mathrm{IC} 50=0.55 \mathrm{mg} / \mathrm{mL})$ in comparison with Arabica CS extract. Chlorogenic acid content in samples did not explain the antiglycative properties of the CS extracts, although the MGO trapping capacity was greatly related to the CGA content. The anti- AGE capacity of the samples might be related to the antioxidant capacity of the CS, explained by the phenolic compound content, especially chlorogenic acid, but also by the presence of high molecular weight polymers (melanoidins) formed through Maillard reaction during the roasting of coffee. The synergistic contribution of other constituents of the CS extracts to the antiglycative and carbonyl trapping properties in vitro should not be discarded. Further studies should be performed for evaluating the bioactivity of the extracts in vivo.

\section{Acknowledgments}

This research is funded by the Ministry of Science and Innovation (Spain) under project NATURAGE (AGL20I0-17779) and CSIC-201370E027. M. Navarro is grateful to a JAE-predoc grant from CSIC. The authors wish to thank Fortaleza for supplying coffee samples for the present study.

\section{References}

Baynes, J.W., \& Thorpe, S. R. (1999). Role of oxidative stress in diabetic complications: A new perspective on an old paradigm. Diabetes, 48, I-9.

Borrelli, R. C., Esposito, F., Napolitano, A., Ritieni, A., \& Fogliano, V. (2004). Characterization of a new potential functional ingredient: Coffee silverskin. Journal of Agricultural and Food Chemistry, 52, 1338-1343. Borrelli, R. C., Visconti, A., Mennella, C., Anese,M., \& Fogliano, V. (2002). Chemical characterization and antioxidant properties of coffee melanoidins. Journal of Agricultural and Food Chemistry, 50, 6527-6533.

Bousová, I., Martin, J., Jahodár, L., Dusek, J., Palicka, V., \& Drsata, J. (2005). Evaluation of in vitro effects of natural substances of plant origin using a model protein glycoxidation. Journal of Pharmaceutical and Biomedical Analysis, 37, 957-962.

Bravo, J., Monente, C., Juániz, I., De Peña, M. P., \& Cid, C. (2013). Influence of extraction process on antioxidant capacity of spent coffee. Food Research International, 50, 610-616.

Bresciani, L., Calani, L., Bruni, R., Brighenti, F., \& Del Rio, D. (2014s). Phenolic composition, caffeine content and antioxidant capacity of coffee silverskin. Food Research International, 6I, I96-20I.

Budryn, G., Nebesny, E., Podsddek, A., Zyzelewicz, D., Materska, M., Jankowski, S., et al. (2009). Effect of different extraction methods on the recovery of chlorogenic acids, caffeine and Maillard reaction products in coffee beans. European Food Research and Technology, 228, 913-922. 
Chompoo, J., Upadhyay, A., Kishimoto, W., Makise, T., \& Tawata, S. (201I). Advanced glycation end products inhibitors from Alpinia zerumbet rhizomes. Food Chemistry, 129, 709-7I5.

Contini, M., Baccelloni, S., Massantini, R., \& Anelli, G. (2008). Extraction of natural antioxidants from hazelnut (Corylus avellana L.) shell and skinwastes by longmaceration at room temperature. Food Chemistry, 110, 659-669.

Dávalos, A., Gómez-Cordovés, C., \& Bartolomé, B. (2004). Extending applicability of the oxygen radical absorbance capacity (ORAC-fluorescein) assay. Journal of Agricultural and Food Chemistry, 52, 48-54.

del Castillo, M. D., Ames, J. M., \& Gordon, M. H. (2002). Effect of roasting on the antioxidant activity of coffee brews. Journal of Agricultural and Food Chemistry, 50, 3698-3703.

del Castillo, M. D., Ibáñez, E., Amigo, M., Herrero, M., Plaza, M., \& Ullate, M. (2013). Application of coffee silverskin in anti-aging and functional feed WO 20I3/004873.

Delgado-Andrade, C., \& Morales, F. J. (2005). Unraveling the contribution of melanoidins to the antioxidant activity of coffee brews. Journal of Agricultural and Food Chemistry, 53, I403-1407.

Esquivel, P., \& Jiménez, V. M. (2012). Functional properties of coffee and coffee byproducts. Food Research International, 46, 488-495.

Gugliucci, A., Bastos, D. H. M., Schulze, J., \& Souza, M. F. F. (2009). Caffeic and chlorogenic acids in llex paraguariensis extracts are the main inhibitors of AGE generation by methylglyoxal in model proteins. Fitoterapia, 80, 339-344.

Kim, J., Jeong, I. H., Kim, C. S., Lee, Y. M., Kim, J. M., \& Kim, J. S. (20II). Chlorogenic acid inhibits the formation of advanced glycation end products and associated protein cross-linking. Archives of Pharmacal Research, 34, 495-500.

Kim, H. Y., \& Kim, K. (2003). Protein glycation inhibitory and antioxidative activities of some plant extracts in vitro. Journal of Agricultural and Food Chemistry, 5I, I586-I59I.

Lee, S. C., Prosky, L., \& De Vries, J.W. (1992). Determination of total, soluble and insoluble dietary fiber in foods. Enzymatic-Gravimetric method, MES-TRIS buffer: Collaborative study. Journal of AOAC International, 75, 395-416.

Leon-Carmona, J. R., \& Golano, A. (201I). Is caffeine a good scavenger of oxygenated free radicals? Journal of Physical Chemistry B, II5, 4538-4546.

Lunceford, N., \& Gugliucci, A. (2005). Ilex paraguariensis extracts inhibit AGE formation more efficiently than green tea. Fitoterapia, 76, 419-427.

Martinez-Saez, N., Ullate, M., Martin-Cabrejas, M. A., Martorell, P., Genovés, S., Ramon, D., et al. (20l4). A novel antioxidant beverage for body weight control based on coffee silverskin. Food Chemistry, 150, 227234.

Mesías, M., Navarro, M., Gökmen, V., \& Morales, F. J. (2013). Antiglycative effect of fruit and vegetable seed extracts: Inhibition of AGE formation and carbonyl trapping abilities. Journal of the Science of Food and Agriculture, 93, 2037-2044.

Morales, F. J., Martin, S., Açar, O. C., Arribas-Lorenzo, G., \& Gökmen, V. (2009). Antioxidant activity of cookies and its relationship with heat-processing contaminants: A risk/benefit approach. European Food Research Technology, 228, 345-354.

Moreira, A. S. P., Nunes, F. M., Domingues, M. R., \& Coimbra, M. A. (20I2). Coffee melanoidins: Structures, mechanisms of formation and potential health impacts. Food \& Function, 3, 903-915.

Münch, G., Thome, J., Foley, P., Schinzel, R., \& Riederer, P. (1997). Advanced glycation endproducts in ageing and Alzheimer's disease. Brain Research Reviews, 23, I34-I43.

Nagaraj, R. H., Sarkar, P., Mally, A., Biemel, K. M., Lederer, M. O., \& Padayatti, P. S. (2002). Effect of pyridoxamine on chemical modification of proteins by carbonyls in diabetic rats: Characterization of a major product from the reaction of pyridoxamine and methylglyoxal. Archives of Biochemistry and Biophysics, 402, II0-119.

Nakagawa, T., Yokozawa, T., Tarasawa, K., Shu, S., \& Juneja, L. R. (2002). Protective activity of green tea against free radical- and glucose-mediated protein damage. Journal of Agricultural and Food Chemistry, 50, $2418-2422$.

Napolitano, A., Fogliano, V., Tafuri, A., \& Ritieni, A. (2007). Natural occurrence of ochratoxin A and antioxidant activities of green and roasted coffees and corresponding byproducts. Journal of Agricultural and Food Chemistry, 55, 10499-10504.

Narita, Y., \& Inouye, K. (20I2). High antioxidant activity of coffee silverskin extracts obtained by the treatment of coffee silverskin with subcritical water. Food Chemistry, 135, 943-949. 
Oya, T., Hattori, N.,Mizuno, Y., Miyata, S., Maeda, S., Osawa, T., et al. (1999). Methylglyoxal modification of protein. Chemical and immunochemical characterization of methylglyoxal-arginine adducts. Journal of Biological Chemistry, 274, 18492-18502.

Peng, X., Cheng, K. W., Ma, J., Chen, B., Ho, C. T., Lo, C., et al. (2008a). Cinnamon bark proanthocyanidins as reactive carbonyl scavengers to prevent the formation of advanced glycation endproducts. Journal of Agricultural and Food Chemistry, 56, |907-19|I.

Peng, X., Zheng, Z., Cheng, K.W., Shan, F., Ren, G. X., Chen, F., et al. (2008b). Inhibitory effect of mung bean extract and its constituents vitexin and isovitexin on the formation of advanced glycation endproducts. Food Chemistry, 106, 475-48I.

Pourfarzad, A., Mahdavian-Mehr, H., \& Sedaghat, N. (20I3). Coffee silverskin as a source of dietary fiber in bread-making: Optimization of chemical treatment using response surface methodology. LWT — Food Science and Technology, 50, 599-606.

Povichit, N., Phrutivorapongkul, A., Suttajit, M., Chaiyasut, C. C., \& Leelapornpisid, P. (2010). Phenolic content and in vitro inhibitory effects on oxidation and protein glycation of some Thai medicinal plants. Pakistan Journal of Pharmaceutical Science, 23, 403-408.

Prosky, L., Asp, N. G., Schweizer, T. F., Devries, J. W., \& Furda, I. (1988). Determination of insoluble, soluble and total dietary fiber in foods and food products; interlaboratory study. Journal of AOAC, 7I, I0I7-I023.

Prosky, L., Asp, N. G., Schweizer, T. F., Devries, J. W., \& Furda, I. (1992). Determination of insoluble and soluble dietary fiber in foods and food products; collaborative study. Journal of AOAC International, 75, 360-367.

Rice-Evans, C. A., Miller, N. J., \& Paganga, G. (1996). Structure-antioxidant activity relationships of flavonoids and phenolic acids. Free Radical Biology \& Medicine, 20, 933-956.

Sang, S., Shao, X., Bai,N., Lo, C. Y., Yang, C. S., \&Ho, C. T. (2007). Tea polyphenols (-)-epigallocatechin-3gallate: A new trapping agent of reactive dicarbonyl species. Chemical Research in Toxicology, 20, I8621870.

Silván, J. M., Morales, F. J., \& Saura-Calixto, F. (2010). Conceptual study on Maillardized dietary fiber in coffee. Journal of Agricultural and Food Chemistry, 58, 12244-I2249.

Somoza, V., Lindenmeier, M., Wenzel, E., Frank, O., Erbersdobler, H. F., \& Hofmann, T. (2003). Activityguided identification of a chemopreventive compound in coffee beverage using in vitro and in vivo techniques. Journal of Agricultural and Food Chemistry, 5I, 686I-6869.

Thornalley, P. J. (2003). Use of aminoguanidine (Pimagedine) to prevent the formation of advanced glycation endproducts. Archives of Biochemistry and Biophysics, 4I9, 3I-40.

Thornalley, P. J., Langborg, A., \& Minhas, H. S. (1999). Formation of glyoxal, methylglyoxal and 3deoxyglucosone in the glycation of proteins by glucose. Biochemical Journal, 344, 109-1 16.

Van Dam, R. M., \& Hu, F. B. (2005). Coffee consumption and risk of type 2 diabetes: A systematic review. The Journal of the American Medical Association, 294, 97-104.

Verzelloni, E., Pellacani, C., Tagliazucchi, D., Tagliaferri, S., Calani, L., Costa, L. G., Brighenti, F., Borges, G., Crozier, A., Conte, A., \& Del Rio, D. (20l la). Antiglycative and neuroprotective activity of colon-derived polyphenol catabolites. Molecular Nutrition and Food Research, 55, S35-S43.

Verzelloni, E., Tagliazucchi, D. Del, Rio, D., Calani, L., \& Conte, A. (20l lb). Antiglycative and antioxidative properties of coffee fractions. Food Chemistry, 124, I430-1435.

Vlassara, H. (1996). Advanced glycation end-products and atherosclerosis. Annals of Medicine, 28, 419-426.

Vlassara, H., \& Palace, M. R. (2002). Diabetes and advanced glycation endproducts. Journal of Internal Medicine, 25I, 87-I0I.

Wang, J., Sun, B., Cao, Y., \& Tian, Y. (2009). Protein glycation inhibitory activity of wheat bran feruloyl oligosaccharides. Food Chemistry, II 2, 350-353.

Williams,M. (2004). Clinical studies of advanced glycation end product inhibitors and diabetic kidney disease. Current Diabetes Report, 4, 44I-446.

Wu, J. W., Hsieh, C. L., Wang, H. Y., \& Chen, H. Y. (2009). Inhibitory effects of guava (Psidium guajava L.) leaf extracts and its active compounds on the glycation process of protein. Food Chemistry, II3, 78-84.

$\mathrm{Wu}, \mathrm{C}$. H., \& Yen, G. C. (2005). Inhibitory effect of naturally occurring flavonoids on the formation of advanced glycation endproducts. Journal of Agricultural and Food Chemistry, 53, 3167-3173.

Yen,W. J.,Wang, B. S., Chang, L.W., \& Duh, P. D. (2005). Antioxidant properties of roasted coffee residues. Journal of Agricultural and Food Chemistry, 53, 2658-2663. 
FIGURES AND TABLES

Table I. Characterization of Arabica coffee silverskin (ACS) and Robusta coffee silverskin (RCS) extracts.

\begin{tabular}{lll}
\hline Parameters & ACS extract & RCS extract \\
\hline Fiber & & \\
Total $(\mathrm{mg} / \mathrm{g})$ & $286.89 \pm 19.15 \mathrm{a}$ & $362.18 \pm 13.74 \mathrm{~b}$ \\
Soluble $(\mathrm{mg} / \mathrm{g})$ & $240.15 \pm 19.5 \mathrm{a}$ & $268.04 \pm 6.44 \mathrm{~b}$ \\
Insoluble $(\mathrm{mg} / \mathrm{g})$ & $46.75 \pm 0.34 \mathrm{a}$ & $94.14 \pm 7.30 \mathrm{~b}$ \\
Melanoidins $(\mathrm{mg} / \mathrm{g})$ & $172.67 \pm 3.54 \mathrm{a}$ & $239.46 \pm 8.49 \mathrm{~b}$ \\
CGAs $(\mathrm{mg} / \mathrm{g})$ & 11.18 & 68.52 \\
3-CGA $(\%)$ & 13.43 & 11.97 \\
4-CGA $(\%)$ & 16.26 & 13.28 \\
5-CGA $(\%)$ & 57.75 & 38.45 \\
Caffeine $(\mathrm{mg} / \mathrm{g})$ & 30.26 & 33.98 \\
Browning $\left(\mathrm{A}_{\text {ov }} / \mathrm{g}\right)$ & $94.55 \pm 1.51 \mathrm{a}$ & $106.88 \pm 0.83 \mathrm{~b}$ \\
Total phenolic content $(\mathrm{mg}$ eq GA/g) & $31.00 \pm 0.24 \mathrm{a}$ & $35.41 \pm 0.42 \mathrm{~b}$ \\
ABTS $(\mu \mathrm{mol}$ TEAC/g) & $85.20 \pm 1.91 \mathrm{a}$ & $225.8 \pm 24.8 \mathrm{~b}$ \\
ORAC $(\mu \mathrm{mol} \mathrm{TEAC} / \mathrm{g})$ & $1194 \pm 76.62 \mathrm{a}$ & $1513 \pm 9.99 \mathrm{~b}$ \\
FRAP $(\mu \mathrm{mol} \mathrm{TEAC} / \mathrm{g})$ & $829.8 \pm 38.16 \mathrm{a}$ & $640.1 \pm 39.78 \mathrm{~b}$ \\
DPPH $(\mu \mathrm{mol} \mathrm{TEAC} / \mathrm{g})$ & $219.9 \pm 4.34 \mathrm{a}$ & $231.3 \pm 4.73 \mathrm{~b}$ \\
\hline
\end{tabular}

Results are expressed as mean \pm SD for $n=4$. Different letters mean significant differences.

Figure I. Antiglycative capacity of Arabica and Robusta coffee silverskin extracts (ACS, RCS), caffeine (CFF) and chlorogenic acid (CGA) in the BSA-glucose assay. Concentrations assayed were $0.14,0.7 \mathrm{I}$ and I.42 $\mathrm{mg} / \mathrm{mL}$. Results are expressed as mean $\pm \mathrm{SD}$ for $\mathrm{n}=4$. Aminoguanidine (AG) $(0.6 \mathrm{mg} / \mathrm{mL})$ showed an antiglycative activity of $91.2 \%$. Different letters mean significant differences among the ACS and RCS extracts for a same concentration.

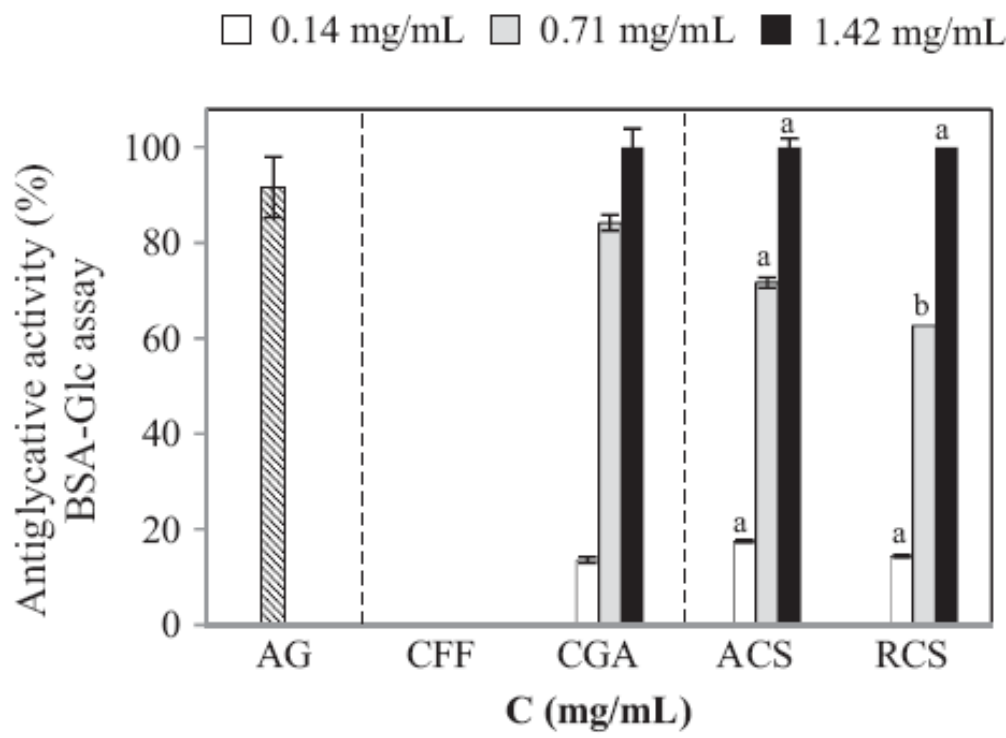


Figure 2. Antiglycative capacity of Arabica and Robusta coffee silverskin extracts (ACS, RCS), caffeine (CFF), and chlorogenic acid (CGA) in the BSA-MGO assay. Concentrations assayed were 0.14, 0.7I and $1.42 \mathrm{mg} / \mathrm{mL}$. Results are expressed as mean \pm SD for $\mathrm{n}=4$. Aminoguanidine $(A G)(0.6 \mathrm{mg} / \mathrm{mL})$ showed an antiglycative activity of $99.2 \%$.

\section{$0.14 \mathrm{mg} / \mathrm{mL} \square 0.71 \mathrm{mg} / \mathrm{mL} \square 1.42 \mathrm{mg} / \mathrm{mL}$}

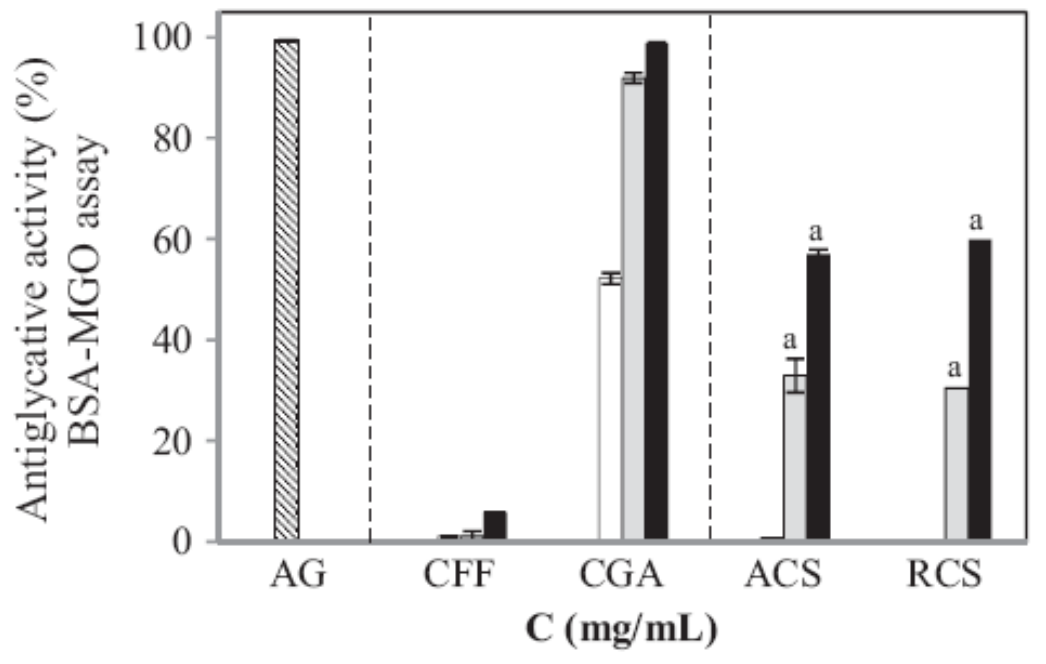

Figure 3. Methylglyoxal trapping capacity of Arabica and Robusta coffee silverskin extracts (ACS, RCS), pyridoxamine (PM), chlorogenic acid (CGA), and caffeine (CFF) at $168 \mathrm{~h}$. Results are expressed as mean \pm SD for $n=4$. PM $(0.1 \mathrm{mg} / \mathrm{mL})$ showed a MGO trapping capacity of $99.6 \%$. $\prec$ ACS; $\longrightarrow$ RCS; $=-$ caffeine; $\rightarrow$ - CGA.

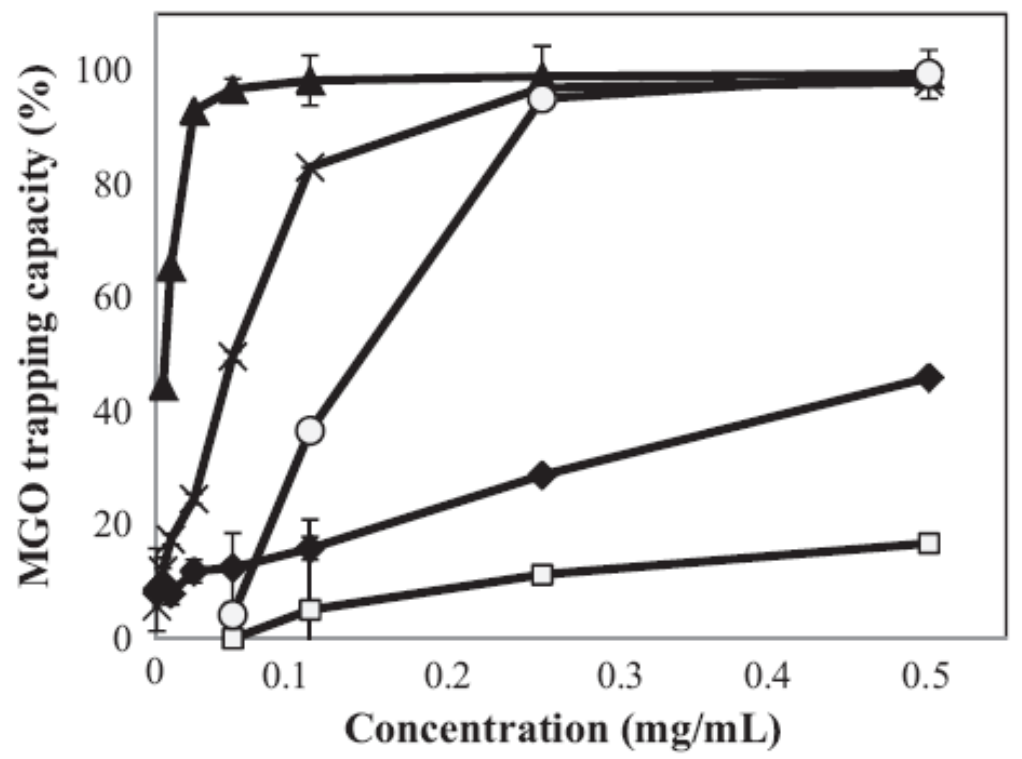


Figure 4. Time-courseMGO trapping capacity of the Arabica and Robusta coffee silverskin extracts (ACS, RCS). Results are expressed as mean $\pm S D$ for $n=4$. Pyridoxamine (PM) $(0.1 \mathrm{mg} / \mathrm{mL})$ showed a MGO trapping capacity of $99.6 \%$. - PM; $\neg$ ACS; $\multimap$ RCS.

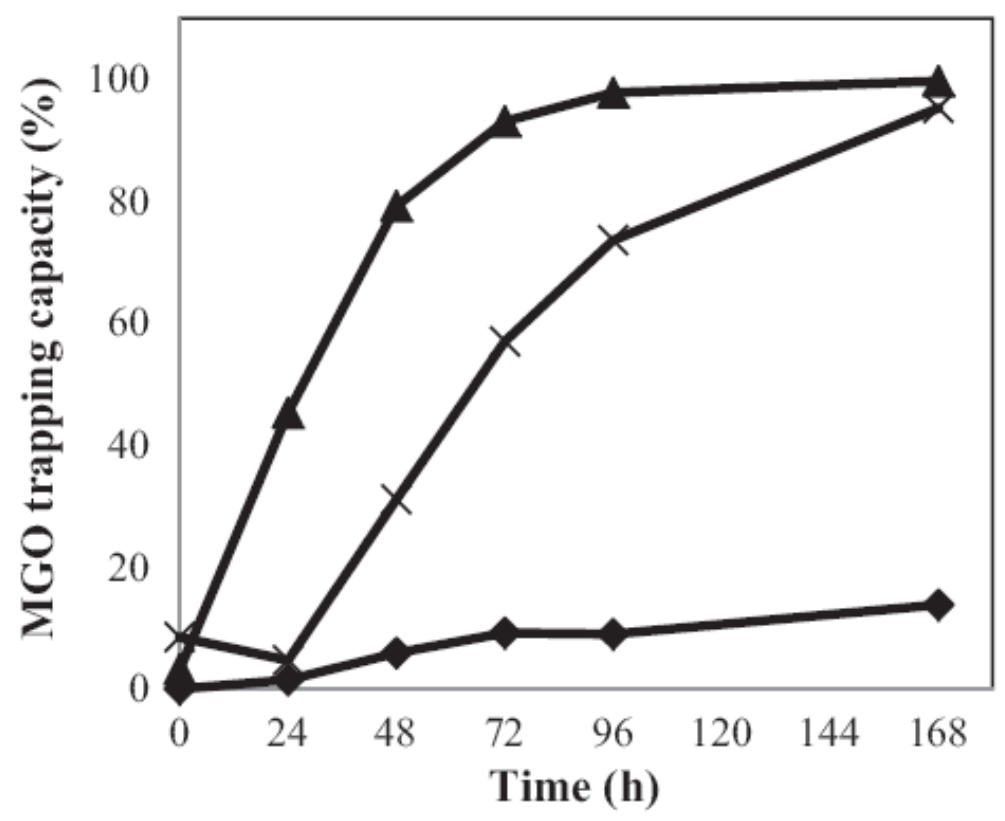

